\title{
Las fusiones y adquisiciones realizadas por empresas españolas en América Latina: un estudio desde la perspectiva del análisis de redes ${ }^{1}$
}

\author{
Ángeles Sánchez Díez, Pablo Galaso Reca \\ y José Manuel García de la Cruz
}

\section{Resumen}

\begin{abstract}
En este artículo se analizan los cambios que experimentaron las empresas españolas dentro del conjunto de inversiones extranjeras mediante fusiones y adquisiciones en América Latina en el período 1999-2012. Las empresas españolas que adquirieron activos locales en América Latina, convirtiéndose en actores líderes a finales de los años noventa, han visto cómo la situación ha cambiado drásticamente con la aparición de nuevos competidores, que ha afectado la importancia de España como inversor en la región. Se emplea la metodología de redes sociales, que permite un análisis más complejo que las aproximaciones más tradicionales, al estudiar la posición de los agentes en función de su pertenencia a una red objeto de análisis. El uso de indicadores de centralidad, densidad y centralización permite observar la estructura de la red y su transformación a través del tiempo y, así, conocer la posición relativa de cada país inversor y, particularmente, de las inversiones españolas.
\end{abstract}

Palabras clave

América Latina, inversiones extranjeras, España, empresas transnacionales, fusiones y adquisiciones de la empresa, competitividad, telecomunicaciones, industria energética, finanzas, análisis de redes

Clasificación JEL

F21, F23

Autores

Ángeles Sánchez Díez es Profesora del Departamento de Estructura Económica y Economía del Desarrollo de la Universidad Autónoma de Madrid, España. angeles.sanchez@uam.es

Pablo Galaso Reca es Investigador del Instituto de Economía de la Universidad de la República, Uruguay. pgalaso@iecon.ccee.edu.uy

José Manuel García de la Cruz es Profesor del Departamento de Estructura Económica y Economía del Desarrollo de la Universidad Autónoma de Madrid, España. manuel.garcruz@ uam.es

Este artículo se ha realizado en el marco del proyecto de investigación "La inversión española en América Latina: retos y oportunidades en el contexto de auge latinoamericano y crisis europea", dirigido por Ángeles Sánchez Díez y financiado por el Centro de Estudios de América Latina (CEAL) de la Universidad Autónoma de Madrid. Los autores agradecen la colaboración de Álex Rodríguez Toscano en el tratamiento de los datos. Todos los autores son miembros del Grupo de Estudio de las Transformaciones de la Economía Mundial (GETEM). 


\section{Introducción}

La inversión extranjera directa (IED) se ha convertido en uno de los elementos centrales del proceso de globalización y de las transformaciones estructurales de la economía mundial. Ello ha repercutido en distintos ámbitos, tales como la redefinición de las nuevas dimensiones geográficas de la economía política, la configuración de nuevas relaciones de poder entre los agentes económicos en los ámbitos nacional e internacional, la revaluación de la importancia de las transferencias de capital financiero y humano entre países o la transferencia de tecnología. Frente a la relevancia de los países desarrollados como origen y destino de las inversiones, en los últimos años se observa la creciente importancia de las economías en desarrollo. En 1990, el 95,3\% de las salidas de inversión extranjera directa y el $83,1 \%$ de las entradas correspondieron a las economías desarrolladas. Sin embargo, en el último decenio los países en desarrollo se han convertido en los principales receptores de inversión extranjera (un 60,8\% del total en 2013), a la vez que sus empresas se están convirtiendo en importantes inversionistas a nivel internacional, con el 39\% de la IED (UNCTAD, s/f). Esto se explica en gran parte por el éxito de las economías emergentes y el declive de la tríada conformada por los Estados Unidos, la Unión Europea y el Japón. Las transformaciones a nivel mundial no se están produciendo solo en el terreno estrictamente económico, sino también en otros espacios de poder como el tecnológico, el político-diplomático y el militar, entre otros, lo que tiene repercusiones en el ámbito público (Estados) y en el privado (transnacionales), planteando nuevas dificultades en la gobernanza de las economías nacionales, como lo ha sintetizado Rodrik (2011) en lo que denomina el trilema político de la economía internacional.

Este es el marco internacional en que se desenvuelven la economía española y sus empresas, que iniciaron su internacionalización a mediados de la década de 1990, concentrándose geográficamente en América Latina y sectorialmente en las telecomunicaciones, la energía y las finanzas. Este hecho se explica por la coincidencia temporal de dos factores: i) la necesidad de internacionalización de las empresas españolas como consecuencia del incremento de competencia impulsado por la profundización del mercado interior europeo (1992) y la creación de la Unión Económica y Monetaria (1999), y ii) las necesidades de financiamiento de las economías latinoamericanas para acometer las reformas estructurales impuestas tras la crisis de la deuda externa de los años ochenta y noventa (Sánchez Díez, 2002). Los cambios acontecidos en la economía española, en particular la privatización de empresas públicas y la apertura al exterior, fortalecieron las ventajas de propiedad de algunas grandes empresas nacionales, mientras que la apertura de las cuentas de capital, la liberalización de los sectores regulados y los procesos de privatizaciones en gran parte de las economías latinoamericanas mejoraron las ventajas de localización de dicha región, en el sentido señalado por Dunning (1988 y 1994).

En la actualidad, el contexto en que las empresas españolas invierten en América Latina es muy diferente al que encontraron hace dos décadas, debido a los cambios ocurridos tanto en España como en esa región. España atraviesa una profunda crisis que tiene indudables repercusiones sobre el comportamiento de las empresas nacionales, las cuales, si bien no han decidido desinvertir masivamente en el exterior, sí se han visto impulsadas a reordenar sus activos internacionales. Por otro lado, América Latina ha registrado elevadas tasas de crecimiento económico, sostenidas por el dinamismo de la demanda interna y de los países emergentes, en un marco de estabilidad macroeconómica y saneamiento de las cuentas del sector público. Así, muchos países han ido articulando políticas más sofisticadas de atracción de inversión extranjera, priorizando la "calidad" frente a la "cantidad", a la vez que algunas empresas latinoamericanas han comenzado a internacionalizarse.

Ante este nuevo escenario, en este artículo se aborda el análisis de la posición inversora de las empresas españolas en América Latina y su alteración como consecuencia de los cambios antes señalados. Los países cuyas inversiones se analizan son la Argentina, Bolivia (Estado Plurinacional de), el Brasil, Chile, Colombia, Costa Rica, Cuba, el Ecuador, El Salvador, Guatemala, Honduras, México, 
Nicaragua, Panamá, el Paraguay, el Perú, el Uruguay y Venezuela (República Bolivariana de), dentro de la región, y Alemania, China, España, los Estados Unidos, Francia, el Japón, Italia, Portugal, el Reino Unido y la Unión Económica Bélgica-Países Bajos-Luxemburgo (BENELUX), de fuera de la región.

Los objetivos de este artículo son:

- Objetivo 1: estudiar la dinámica de fusiones y adquisiciones de empresas en América Latina durante el período comprendido entre 1999 y 2012, particularmente en relación con el grado de interacción entre países y la concentración geográfica.

- Objetivo 2: evaluar el rol desempeñado por empresas españolas en las fusiones y adquisiciones en América Latina frente a sus potenciales competidores, observando su evolución a lo largo del período estudiado. De esta forma, se podrá analizar si España está perdiendo o no la posición de liderazgo que alcanzó en la segunda mitad de la década de 1990. En términos de análisis de redes, se analizará si se está produciendo un desplazamiento desde posiciones centrales a otras más periféricas.

- Objetivo 3: analizar la dinámica de fusiones y adquisiciones en los sectores de las telecomunicaciones, la energía y las finanzas. Se busca contrastar si existen diferencias significativas derivadas de las actividades económicas y observar la posición que ocupan las empresas españolas en cada sector.

Para abordar estos objetivos, se ha empleado la metodología del análisis de redes sociales. La elección de esta herramienta se justifica por su gran capacidad explicativa, contrastada en diversas investigaciones anteriores, para estudiar realidades basadas en interdependencias económicas. En este trabajo, el análisis de redes permite estudiar, desde una perspectiva sistémica, las complejas dinámicas de interacción, influencias e interdependencias entre países, que van más allá de los datos financieros sobre fusiones y adquisiciones de empresas en América Latina.

Luego de esta Introducción, en la segunda sección se revisan los referentes teóricos de la inversión extranjera directa y la aplicación del análisis de redes sociales al estudio de las relaciones económicas internacionales. En la tercera sección, se describen los principales aspectos metodológicos de la construcción, la interpretación y el análisis de las redes de fusiones y adquisiciones. En la cuarta sección, se realiza el análisis de red de las fusiones y adquisiciones de empresas en América Latina y la posición que ocupa España frente a sus competidores, presentando el estudio dinámico del período 1999-2012 y el estudio estático de los sectores de telecomunicaciones, energía y finanzas. Finalmente, en la quinta sección, se presentan las conclusiones de este artículo.

\section{Referentes teóricos de las fusiones y adquisiciones y del análisis de redes sociales}

Dunning $(1977,1979,1980$ y 1988) sintetizó las aportaciones de diferentes autores al estudio de la IED en el denominado paradigma ecléctico, señalando que la inversión extranjera directa tendría lugar ante la presencia de ventajas de propiedad, de localización del país de destino² y de internalización (lo que se conoce como modelo o paradigma OLI). De la escuela de la organización industrial, recogió las contribuciones de Hymer (1976 y 1979), Kindleberger (1969), Caves (1971, 1980 y 1982) y Caves y Hirschey (1981), que dieron lugar a las denominadas ventajas de propiedad, es decir, las capacidades específicas que las empresas multinacionales tienen en propiedad exclusiva frente a las empresas locales. No obstante, las ventajas de propiedad, aunque necesarias, no son suficientes para que una

\footnotetext{
2 Con posterioridad se ha comenzado a analizar la importancia de los factores de localización en los países de origen de las empresas transnacionales. Véase Dunning (2009), entre otros, en relación con aportaciones teóricas, así como Álvarez y Torrecillas (2013), en relación con evidencia empírica.
} 
compañía invierta en el exterior. Se requiere la presencia de alguna ventaja de localización en el país de destino, elemento analizado por las teorías de localización. Asimismo, incluyó los aportes de la teoría de internalización, concretamente de Williamson (1975), Casson (1979 y 1985), Rugman (1976, 1980 y 1981) y Tecee (1986), quienes partían de la hipótesis de que la internacionalización de las empresas es un mecanismo para disminuir los costos de transacción resultantes de la imperfección del funcionamiento de los mercados.

Entre las críticas de las que ha sido objeto el paradigma OLI destaca el hecho de que no permite explicar con claridad la inversión originada en los países en desarrollo, dado que en su mayoría las empresas de esos países no cuentan con ventajas exclusivas de propiedad. Según Moon y Roehl (2001), las empresas transnacionales de los países emergentes persiguen con su internacionalización su propio fortalecimiento, sobre la base de la acumulación de recursos y activos a los que previamente no tenían acceso. El propio Dunning (2009) ha introducido matices a sus reflexiones teóricas, afirmando que la búsqueda de conocimientos y experiencias de aprendizaje puede estar motivando la internacionalización de las empresas de dichos países en ausencia de las clásicas ventajas de propiedad, idea previamente planteada por Luo y Tung (2007). En resumen, la expansión internacional de las empresas de los países en desarrollo se puede interpretar a la luz del denominado marco analítico de vinculación, apalancamiento y aprendizaje (modelo LLL) (CEPAL, 2014; Mathews, 2006), según el cual las empresas a través de alianzas de distinta índole acceden a recursos a los que con anterioridad no tenían acceso. De esta forma, las empresas que se han iniciado más tarde en la internacionalización pueden aprovechar la experiencia y el conocimiento con que cuentan otras empresas.

Queda claro, en cualquier caso, que la recepción de empresas extranjeras representa una oportunidad para las empresas nacionales de apropiación de las externalidades que las inversiones extranjeras generan en las economías de destino, mejorando su atractivo de localización para inversiones futuras, como plantea el paradigma OLI, pero también que puede contribuir a que empresas nacionales, como sugiere el modelo LLL, se inicien en estrategias de internacionalización.

Por estos motivos, a pesar de tratarse de un tema controvertido ${ }^{3}$, se asumen dos supuestos:

i) La presencia de empresas transnacionales en una determinada economía se puede traducir en transformaciones en el tejido productivo a través de los denominados efectos de transvase (Aitken y Harrison, 1999): una adquisición o fusión puede producir la transferencia de ciertas ventajas de propiedad al activo local comprado. Estas transferencias se entienden como flujos de información, conocimientos, aprendizaje en formas de organización, capital humano, financiamiento y tecnología. Además, la economía que adquiere activos en el exterior también puede recibir efectos de transvase en la forma de flujos de conocimiento, nuevas prácticas empresariales o recursos humanos.

ii) Las empresas transnacionales pueden contribuir a que las firmas nacionales modernicen sus procesos de producción y de capacitación, y la calidad de su producción (Blomström y Kokko, 2003): debido a los efectos de transvase, los dos países participantes en una operación transfronteriza pueden obtener beneficios específicos de estas relaciones con impacto en sus estructuras económicas ${ }^{4}$.

Dado que los países - a través de sus empresas - habitualmente llevan a cabo operaciones de fusiones y adquisiciones con varios países, los mencionados efectos de transvase terminan produciéndose de forma multilateral, como se muestra en el diagrama 1.

\footnotetext{
3 Véase un resumen de las posiciones sobre este tema en el recuadro I.1 de CEPAL (2011, pág. 29).

4 La difusión de los beneficios y su impacto estructural no serán ni automáticos, ni necesariamente directos y no se producirán, necesariamente, en todas las operaciones de fusión o adquisición. Las políticas públicas son determinantes en la definición de los resultados finales.
} 


\section{Diagrama 1}

Ejemplo de transvases multilaterales en las operaciones de fusiones y adquisiciones transfronterizas de empresas

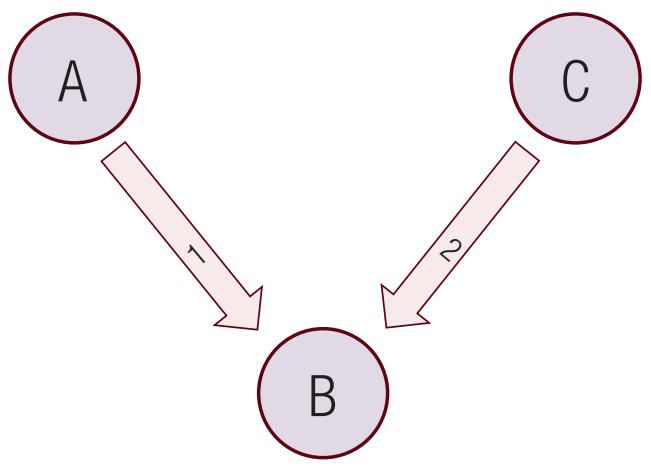

Fuente: Elaboración propia.

El vínculo 1 representa las adquisiciones que empresas del país A realizan de empresas del país B, lo que supone un flujo de inversión extranjera directa de A hacia B. Por su parte, el vínculo 2 refleja una realidad análoga con los países $\mathrm{B}$ y $\mathrm{C}$ como protagonistas. Las operaciones representadas en el vínculo 1 pueden generar transformaciones en los países A y B, y asimismo, de forma indirecta, también podrían producirlas en el país $\mathrm{C}$, por medio del vínculo 2. En otras palabras, los transvases de información, conocimientos, aprendizaje en formas de organización, capital humano, financiamiento y tecnología no se limitan exclusivamente a vínculos directos entre dos países, sino que circulan de unos a otros a través de interacciones múltiples, en el marco de la lógica de la existencia de una red. Por ello, resulta indispensable considerar simultáneamente el conjunto de relaciones entre países para comprender de forma adecuada estos flujos.

Como ya se ha anticipado, el análisis de las fusiones y adquisiciones transfronterizas se realiza a través de la metodología de redes sociales, de forma que se van a observar las características de las unidades sociales individuales como resultado de procesos estructurales o relacionales (Wasserman y Faust, 1994, pág. 7). A grandes rasgos, entre los trabajos referentes a dicha metodología se incluyen estudios teóricos sobre la formación y evolución de redes (Watts y Strogatz, 1998; Jackson y Wolinsky, 1996), trabajos empíricos acerca de las estructuras y patrones de las redes en el mundo real (Bearman, Moody y Stovel, 2004; Fagiolo, Reyes y Schiavo, 2009) y análisis metodológicos que proporcionan nuevas herramientas de investigación (Wasserman y Faust, 1994; Jackson, 2008).

En el estudio de la economía, esta metodología se ha utilizado en el análisis de la estructura y funcionamiento de los mercados competitivos (Mitchell y Skrzypacz, 2006; Amir y Lazzati, 2011), el empleo y la desigualdad salarial (Calvó-Armengol y Jackson, 2004), la difusión de información e innovaciones (Schilling y Phelps, 2007; Fleming, King y Juda, 2007; Galaso, 2011) o los patrones que rigen el comercio internacional (Kali y Reyes, 2006; De Benedictis y otros, 2013).

Existe también una creciente literatura académica en que se emplea el análisis de redes para estudiar los flujos financieros internacionales en general, aunque su aplicación al análisis de la inversión extranjera todavía es relativamente escasa. Algunos trabajos se han centrado en analizar las crisis financieras internacionales (Chinazzi y otros, 2013; Elliott, Golub y Jackson, 2014), así como la estructura de participaciones accionarias entre empresas transnacionales (Vitali, Glattfelder y Battiston, 2011; Vittali y Battiston, 2013). Haberly y Wojcik (2013) se centran en la red de inversión extranjera directa originada en los paraísos fiscales y muestran una gran concentración de los flujos y una alta dependencia respecto de similitudes políticas y sociales entre países, en tanto que Visintin (2011) analiza las redes internacionales de comercio e IED, en las que se revela una estructura de centro y periferia. 


\section{Metodología: construcción y análisis de las redes de fusiones y adquisiciones}

A continuación se detallan los aspectos metodológicos de la construcción de las redes aplicadas al caso de las fusiones y adquisiciones transfronterizas de empresas y el análisis de los resultados obtenidos.

\section{Construcción de las redes}

Para la aplicación de esta metodología se requiere, en este caso, disponer de una matriz de doble entrada de los flujos económicos que tuvieron lugar entre pares de países en el período comprendido entre 1999 y 2012. No existe información a nivel mundial sobre inversión extranjera directa desagregada según origen y destino ni por sector para todos los países, por lo que se ha optado por construir la matriz a partir de la base de datos sobre fusiones y adquisiciones transfronterizas elaborada por Thomson Reuters. Se han calculado: 1 matriz y 1 red para todo el período y todos los sectores, 7 matrices y 7 redes bienales (con la excepción de un caso en que son trienales y uno en que corresponden a solo un año, al final del período) y 3 matrices y 3 redes sectoriales. Es decir, se han calculado 11 matrices y 11 redes, así como sus indicadores asociados.

Toda red precisa de dos elementos básicos: los nodos y los vínculos. En el presente análisis, los nodos corresponden a las 28 economías nacionales incluidas en el estudio, mencionadas con anterioridad, y los vínculos representan el valor total (en millones de dólares) de las compras realizadas por empresas de un país a empresas de otro país. De la base de datos utilizada se seleccionaron todas las operaciones en las que al menos una de las dos empresas implicadas - ya sea la compradora o la vendedora - se sitúa en algún país de América Latina; dicho de otra manera, no se incluyeron las relaciones entre dos economías no latinoamericanas ${ }^{5}$.

A modo de ejemplo, en el cuadro 1 se presenta una simplificación de la base de datos, con tres operaciones entre empresas de dos países. Por medio de la agregación de estas operaciones, se calculan los dos vínculos que conectan a ambos países, como se ilustra en el diagrama 2.

Cuadro 1

Muestra de la base de datos utilizada para la construcción de las redes de fusiones y adquisiciones transfronterizas de empresas

\begin{tabular}{cccccc}
\hline \multicolumn{2}{c}{ Comprador } & & \multicolumn{2}{c}{ Vendedor } & Cuantía de la operación \\
\cline { 1 - 2 } Empresa & País & & Empresa & País & \\
\hline 1 & A & 2 & B & 100 \\
\hline 3 & A & 4 & B & 50 \\
\hline 5 & B & 6 & A & 200 \\
\hline
\end{tabular}

Fuente: Elaboración propia.

\section{Diagrama 2}

Ejemplo de dos vínculos entre países en operaciones de fusiones y adquisiciones de empresas
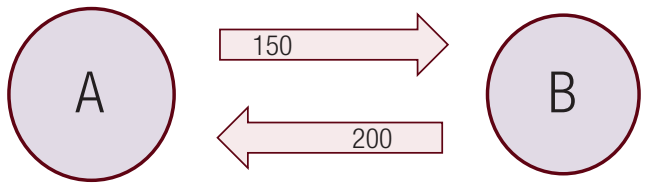

Fuente: Elaboración propia.

5 Por ejemplo, se incluye en este análisis una compra que una empresa francesa realiza de un activo colombiano y viceversa, así como la adquisición de una compañía chilena por parte de una brasileña, pero se excluyen las operaciones entre compañías francesas y españolas. 
Una vez conocidos los vínculos, se analiza su dirección y su ponderación. La dirección depende de dónde se sitúen las empresas compradoras y dónde las vendedoras. En el diagrama 2 se muestra un vínculo que va desde $A$ hacia $B$ y otro que se dirige desde $B$ hacia $A$. Disponer de vínculos con dirección permite diferenciar entre flujos de entrada y flujos de salida, lo que amplía las opciones de cálculo e interpretación de indicadores de red. Por lo tanto, se trata de una red o grafo dirigido, es decir, en que los vínculos se pueden analizar en ambos sentidos. La ponderación corresponde al valor total de las compras de empresas de un país en otro. Así, en el diagrama 2 la ponderación del vínculo que va desde $A$ hacia $B$ es de 150, resultado de la suma de las fusiones entre las empresas 1 y 2 , por un lado, y 3 y 4, por otro; asimismo, el vínculo que se dirige desde B hacia A tiene un valor de 200, que equivale a la fusión entre las empresas 5 y 6 . Esto permite tener en cuenta cuáles son las conexiones más importantes en la red y cuáles resultan menos relevantes. Trazando simultáneamente todos los vínculos entre los 28 países, se obtiene la red completa de fusiones y adquisiciones de empresas en América Latina.

\section{Análisis de las redes}

Para estudiar la dinámica de fusiones y adquisiciones de empresas en América Latina (objetivo 1) se analizan la red completa, que incluye los datos de todos los años, y las siete redes temporales. El estudio de estas redes se lleva a cabo desde una perspectiva global, es decir, empleando indicadores que describen la estructura de la red en su conjunto, sin distinguir la posición que ocupa cada país. Concretamente, se utilizan los indicadores de densidad y centralización de grado total, que miden las propiedades estructurales relativas a los patrones de interacción colectiva entre todos los países incluidos. La interpretación de estos indicadores es la siguiente:

- La densidad mide la proporción de vínculos existentes en una red respecto del máximo de vínculos posibles ${ }^{6}$. Sirve para cuantificar el grado de conexión entre actores. En el caso de este trabajo, se emplea para medir el nivel total de interacción entre países.

- El indicador de centralización de grado total mide la concentración en la distribución de vínculos entre los nodos de la red, es decir, la concentración de las operaciones de fusiones y adquisiciones por países. Por ello, permite cuantificar si estas operaciones se concentran en unos pocos países que canalizan recursos, aglutinan efectos de transvase y ejercen su influencia sobre el resto o, por el contrario, si los vínculos de fusiones y adquisiciones se establecen de forma relativamente distribuida, con la participación de múltiples centros de acción.

Posteriormente, se analiza el rol desempeñado por España y su evolución a lo largo del período estudiado, tanto en la red completa de datos de todos los años como en las siete redes temporales (objetivo 2). El estudio se realiza a través de indicadores que describen la posición relativa que ocupa cada país en las redes. En particular, se calculan cuatro medidas de centralidad: de grado de entrada, de grado de salida, de grado total y de vector propio. El cálculo se realiza de la siguiente forma:

- La centralidad de grado corresponde al número de vínculos que posee un nodo ponderado por el valor de cada vínculo. Es decir, es el número de conexiones que mantiene un país con el resto, ponderado por el valor, en millones de dólares, de las operaciones que dichas conexiones representan. En grafos dirigidos (como los utilizados en este análisis) se pueden definir tres medidas distintas de centralidad de grado: de entrada, de salida y total. Su cálculo es análogo, pero se realiza considerando, respectivamente, los vínculos que llegan al nodo, los que salen de él y la suma de ambos; esto es, el volumen de inversión recibida por el país debido a ventas de empresas a compañías extranjeras (centralidad de grado de entrada), los

6 Los vínculos adquieren su número máximo si al menos una empresa de cada uno de los 28 países considerados realiza una adquisición de una empresa en cada uno de los 27 países restantes. 
flujos emitidos por empresas del país por concepto de pago por la adquisición de activos en el exterior (centralidad de grado de salida) y la combinación de ambos (centralidad de grado total).

- La centralidad de vector propio (Bonacich, 1972) mide la capacidad de influencia de un nodo, en este caso de un país. Aquellos nodos (países) que presentan elevados valores de este indicador están ligados a otros que, a su vez, están bien conectados. Por ello, son adecuados para ejercer influencia, difundir información o propagar los efectos de transvase.

Finalmente, con el fin de estudiar los sectores de telecomunicaciones, energía y finanzas (objetivo 3), se requiere el uso de las redes sectoriales. A partir de ellas se calculan todos los indicadores anteriores y, de esta forma, se pueden analizar tanto los patrones de interacción colectiva entre los países como la posición relativa de España en los tres sectores de actividad seleccionados.

En el cuadro 2 se describen con mayor detalle la relación entre los objetivos de este trabajo, los conceptos económicos asociados, los indicadores de red que se utilizarán para el análisis y su forma de cálculo.

\section{Cuadro 2}

Principales indicadores de red propuestos para el análisis

\begin{tabular}{|c|c|c|c|}
\hline $\begin{array}{l}\text { Objetivos } \\
\text { del artículo }\end{array}$ & Concepto económico asociado & Indicador de red ${ }^{\mathrm{a}}$ & Cálculob \\
\hline \multirow[b]{2}{*}{1 y 3} & $\begin{array}{l}\text { Interacción entre los países } \\
\text { en los procesos de fusiones y } \\
\text { adquisiciones de empresas }\end{array}$ & Densidad & $\begin{array}{l}D=\frac{V}{\max (V)} \\
\text { donde } V \text { es el número de vínculos existentes en la red y max } \\
(V) \text { es el número máximo de vínculos que podría registrar la red } \\
\text { si todos los nodos estuvieran conectados con todos. }\end{array}$ \\
\hline & $\begin{array}{l}\text { Concentración geográfica de } \\
\text { las fusiones y adquisiciones } \\
\text { de empresas }\end{array}$ & $\begin{array}{l}\text { Centralización } \\
\text { de grado total }\end{array}$ & $\begin{array}{l}C G T=\frac{\sum_{u=1}^{u=|N|} C G_{\text {tot }}\left(u^{*}\right)-C G_{\text {tot }}(u)}{\max \left(\sum_{u=1}^{u=|N|} C G_{\text {tot }}\left(u^{*}\right)-C G_{\text {tot }}(u)\right)} \\
\text { donde } N \text { es el número de nodos de la red, } u \text { representa a un nodo } \\
\text { cualquiera de la red, } C G_{\text {tot }}(u) \text { es la centralidad de grado total del } \\
\text { nodo } u \text { y } C G_{\text {tot }}\left(u^{*}\right) \text { es la máxima centralidad de grado total } \\
\text { registrada por un nodo de la red. }\end{array}$ \\
\hline \multirow{4}{*}{2 у 3} & \multirow[t]{2}{*}{$\begin{array}{l}\text { Importancia relativa de un país } \\
\text { en las fusiones y adquisiciones } \\
\text { de empresas de la región }\end{array}$} & $\begin{array}{l}\text { Centralidad de } \\
\text { grado total }\end{array}$ & $\begin{array}{l}C G_{t o t}(u)=\sum_{v=1, v \neq u}^{|N|} w_{v, u}+\sum_{v=1, v \neq u}^{|N|} w_{u, v} \\
\text { donde } N \text { es el número de nodos de la red, } v \text { representa a un } \\
\text { nodo cualquiera de la red, } W_{v, u} \text { es el valor del vínculo que se } \\
\text { dirige desde el nodo } v \text { hacia el nodo } u \text { y } W_{u, v} \text { es el valor del } \\
\text { vínculo que se dirige desde el nodo } u \text { hacia el nodo } v \text {. }\end{array}$ \\
\hline & & $\begin{array}{l}\text { Centralidad de } \\
\text { vector propio }\end{array}$ & $\begin{array}{l}\lambda C V P=W \cdot C V P \\
\text { donde } W \text { es la matriz de adyacencia, es decir, la matriz cuadrada } \\
\text { donde se representan todos los vínculos de la red, y } \lambda \text { es el } \\
\text { máximo valor propio de la matriz de adyacencia. }\end{array}$ \\
\hline & $\begin{array}{l}\text { Importancia relativa de un país } \\
\text { en las fusiones y adquisiciones } \\
\text { de la región (según las } \\
\text { empresas compradoras) }\end{array}$ & $\begin{array}{l}\text { Centralidad de } \\
\text { grado de salida }\end{array}$ & $\begin{array}{l}C G_{\text {sal }}(u)=\sum_{v=1, v \neq u}^{|N|} w_{u, v} \\
\text { donde } N \text { es el número de nodos de la red, } v \text { representa a un nodo } \\
\text { cualquiera de la red y } W_{u, v} \text { es el valor del vínculo que se dirige } \\
\text { desde el nodo } u \text { hacia el nodo } v \text {. }\end{array}$ \\
\hline & $\begin{array}{l}\text { Importancia relativa de un país } \\
\text { en las fusiones y adquisiciones } \\
\text { de la región (según las } \\
\text { empresas adquiridas) }\end{array}$ & $\begin{array}{l}\text { Centralidad de } \\
\text { grado de entrada }\end{array}$ & $\begin{array}{l}C G_{\text {ent }}(u)=\sum_{v=1, v \neq u}^{|N|} w_{v, u} \\
\text { donde } N \text { es el número de nodos de la red, } v \text { representa a un nodo } \\
\text { cualquiera de la red y } W_{v, u} \text { es el valor del vínculo que se dirige } \\
\text { desde el nodo } v \text { hacia el nodo } u \text {. }\end{array}$ \\
\hline
\end{tabular}

Fuente: Elaboración propia.

a Los indicadores de densidad y de centralización expresan características generales de la red, mientras que los indicadores de centralidad de grado - total, de entrada y de salida - y la centralidad de vector propio permiten observar la posición de un nodo (país) en la red.

b Los indicadores de centralidad se normalizan dividiéndolos por el máximo valor posible. 


\section{Resultados del análisis de red de las fusiones y adquisiciones en América Latina}

A continuación se presentan los resultados del análisis de red de las fusiones y adquisiciones de empresas en América Latina en el período comprendido entre 1999 y 2012. En primer lugar, se estudia la dinámica general de las fusiones y adquisiciones en la región; posteriormente, se procede a analizar el papel desempeñado por España y, por último, el análisis se centra en los sectores de las telecomunicaciones, la energía y las finanzas.

\section{La dinámica de las fusiones y adquisiciones en América Latina}

Se analizan, en primer término, las propiedades estructurales de la red global correspondiente a los años estudiados (véanse el gráfico 1 y el cuadro 3), centrándose en el grado de interacción entre países (densidad) y en la concentración geográfica de este tipo de operaciones en la región (centralización). Los resultados ponen de relieve dos aspectos destacables:

- $\quad$ El grado de interacción entre países, medido con el indicador de densidad de la red, es más elevado en los períodos 2007-2009 y 2010-2011. Esto es el reflejo de una transformación importante en la reordenación de activos productivos en América Latina. A finales de la década de 1990 e inicios de la década de 2000, las adquisiciones de empresas en la región eran realizadas por compañías de un número reducido de países. Destacaban las compañías españolas, que aprovecharon los procesos de privatización que se produjeron en la gran mayoría de las economías latinoamericanas. Sin embargo, la realidad de la región se transformó rápidamente. El fortalecimiento de las empresas latinoamericanas y el auge de sus operaciones en el exterior han incrementado el grado de interacción entre los países de la región, más aún teniendo en cuenta que la gran mayoría de las empresas translatinas tienen sus activos en el extranjero localizados en países de la propia América Latina. A ello hay que sumar el creciente interés mostrado por empresas chinas, que presentan una dinámica muy agresiva en la extracción de recursos naturales, y por las compañías estadounidenses que, aunque con ciclos, siempre han estado presentes en la región.

- En cuanto a la concentración geográfica de las fusiones y adquisiciones, se observa que el indicador de centralización de grado total alcanza los niveles máximos en el período 20072009, lo que pone de manifiesto que las cuantiosas operaciones de fusiones - observadas en el incremento de la densidad-tendieron progresivamente a concentrarse en un menor número de países. Además, a partir de 2010, los niveles del indicador se mantienen por encima de los registrados en la primera mitad de la década de 2000 , lo que muestra que las oportunidades de fusiones y adquisiciones en el período posterior a la crisis financiera internacional están siendo aprovechadas por un menor número de países. Es decir, se refleja una tendencia hacia una estructura de red en que la mayoría de los países se encuentran relativamente al margen de las operaciones transfronterizas de fusiones y adquisiciones de empresas, mientras unos pocos aglutinan la mayoría de los vínculos de entrada y salida de inversiones. 
Gráfico 1

Red de fusiones y adquisiciones transfronterizas de empresas en América Latina, 1999-2012

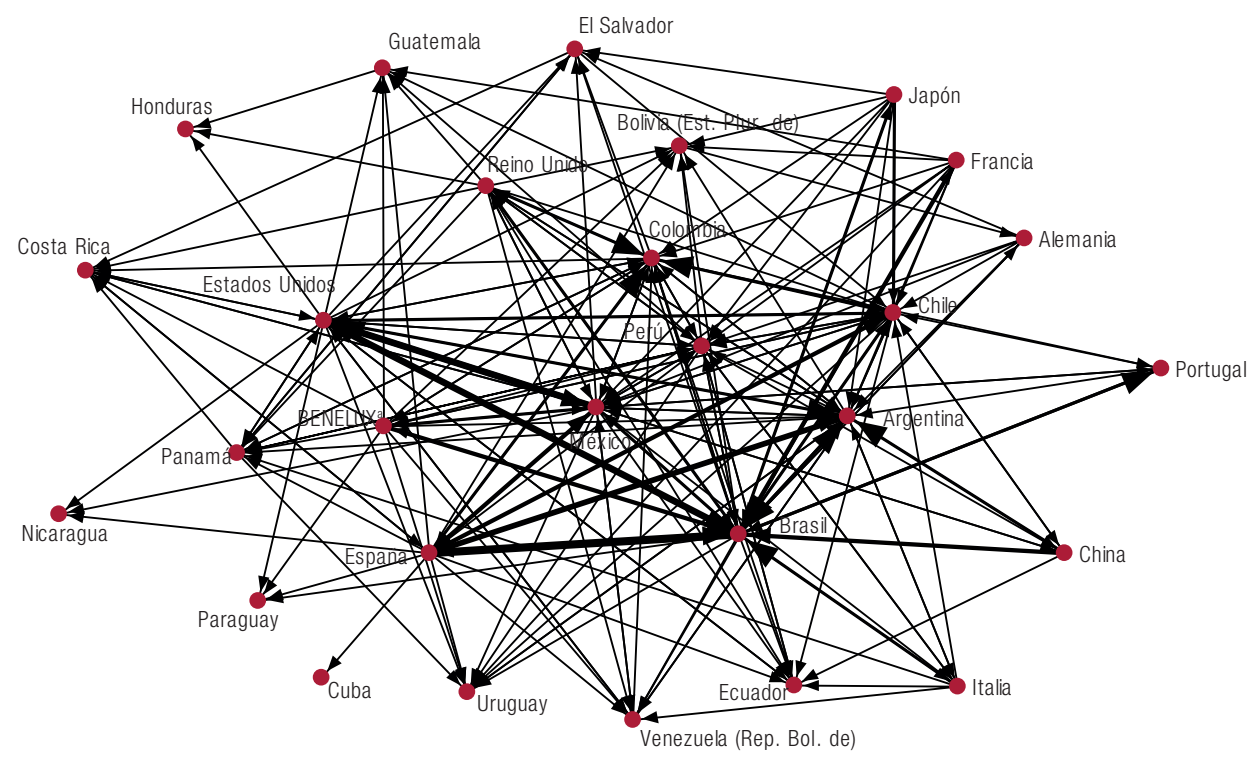

Fuente: Elaboración propia, sobre la base de datos de Thomson Reuters.

a Unión Económica Bélgica-Países Bajos-Luxemburgo.

Cuadro 3

Características estructurales de la red de fusiones y adquisiciones transfronterizas de empresas en América Latina, 1999-2012

\begin{tabular}{lccccccc}
\hline & $1999-2000$ & $2001-2002$ & $2003-2004$ & $2005-2006$ & $2007-2009$ & $2010-2011$ & 2012 \\
\hline Densidad & 0,118 & 0,101 & 0,091 & 0,106 & 0,159 & 0,143 & 0,081 \\
\hline Centralización de grado total & 0,044 & 0,03 & 0,038 & 0,050 & 0,106 & 0,073 & 0,051 \\
\hline
\end{tabular}

Fuente: Elaboración propia.

\section{El rol de España en las fusiones y adquisiciones en América Latina}

A continuación, el análisis está centrado en el papel desempeñado por España en la red de fusiones y adquisiciones de empresas en América Latina. Con este fin, se estudia la posición que ocupa en relación con el resto de los países (nodos) de la red. Se presta especial atención a la comparación con países que vienen mostrando un gran dinamismo en los últimos años, como el Brasil, los Estados Unidos y China.

Los indicadores de centralidad de grado total por países (véase el gráfico 2) muestran que existe un conjunto reducido de países con niveles superiores de centralidad, frente al elevado número de aquellos que ocupan posiciones más periféricas, es decir, de aquellos cuyos flujos de fusiones y adquisiciones (vínculos) con el resto son menores. La situación de los países más centrales refleja que sus empresas han establecido contactos, a través de las fusiones y adquisiciones, con empresas de un conjunto amplio de países, ya sea como compradoras (centralidad de salida) o adquiridas (centralidad de entrada). 


\section{Gráfico 2}

Países seleccionados: indicadores de centralidad de grado en las fusiones y adquisiciones transfronterizas de empresas, 1999-2012

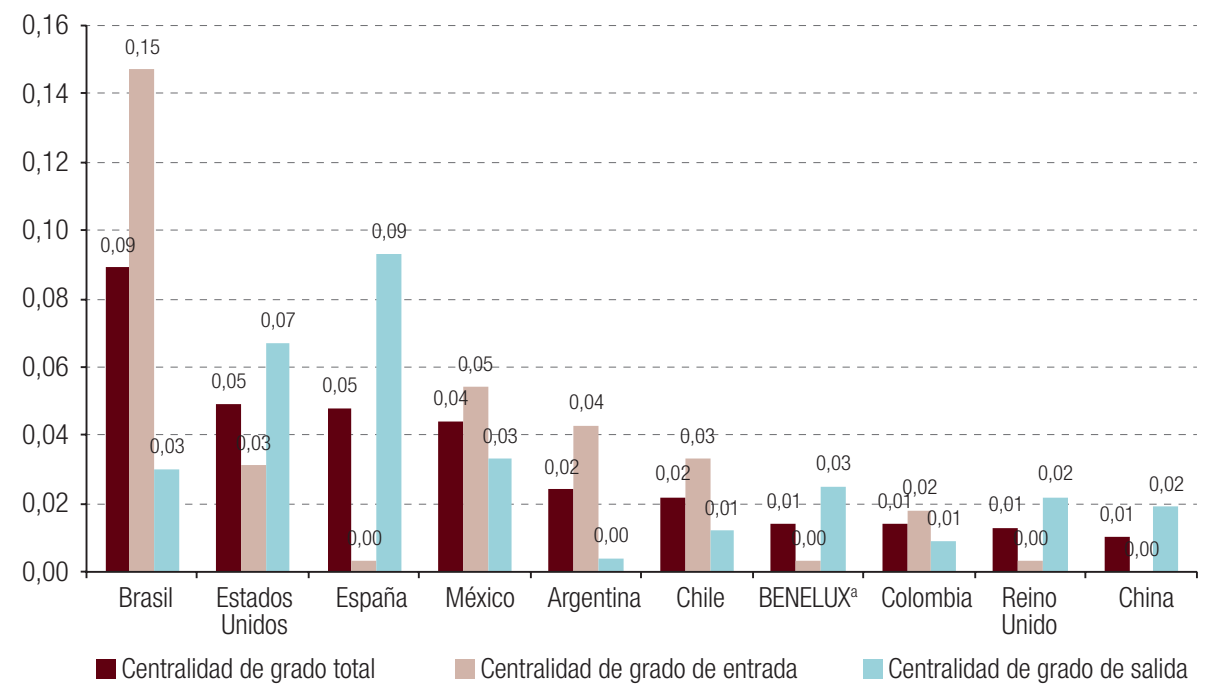

Fuente: Elaboración propia.

a Unión Económica Bélgica-Países Bajos-Luxemburgo.

En el período total estudiado, destaca el protagonismo del Brasil, los Estados Unidos, España y, en menor medida, México, la Argentina y Chile. Estas son las economías que, desde una perspectiva global, se sitúan en el centro de la red - según el indicador de centralidad de grado total-, manteniendo más interacciones con la totalidad de los agentes que participan en la red. Existen notables diferencias entre ellas, sobre todo al considerar su posición diferenciada como países de origen de las empresas compradoras o vendedoras de activos. Atendiendo a los supuestos asumidos, estas economías son las más relevantes en relación con su potencialidad como canalizadoras de los efectos de transvases (Aitken y Harrison, 1999), es decir, su potencialidad para facilitar los flujos de información, conocimientos, aprendizaje en formas de organización, capital humano, financiamiento y tecnología, al mismo tiempo que presentan más posibilidades de modernizar sus procesos de producción, capacitación y localidad en la producción (Blomström y Kokko, 2003) y de que estos puedan generar transformaciones en sus estructuras económicas.

España y los Estados Unidos, seguidos por México, el Brasil y la Unión Económica Bélgica-Países Bajos-Luxemburgo (BENELUX), muestran un mayor dinamismo en cuanto a la internacionalización de sus empresas, expresado a través de una mayor centralidad de grado de salida. El protagonismo de España radica en el aprovechamiento que hizo durante la década de 1990 de las oportunidades de compra generadas por los procesos de privatizaciones y en la posterior reordenación de activos y ampliación de sus inversiones en la región para consolidar su posición de liderazgo y explotar un mercado que ya le resultaba conocido. Además, aunque los sectores pioneros fueron los de servicios de utilidad pública - telefonía, energía y banca-, muchas otras empresas los siguieron, ya fuera imitando las estrategias o bien operando como proveedores de las empresas españolas previamente instaladas en la región. Aunque la apuesta empresarial de las compañías españolas nunca ha decaído, su intensidad disminuyó en los períodos 2001-2002 y 2005-2006, en que dichas compañías reorientaron sus operaciones en el exterior hacia el mercado europeo, aprovechando la experiencia y el tamaño adquirido en América Latina. Las empresas españolas han reproducido, en cierta medida, las matrices en las filiales en América Latina, que se han creado a través de las adquisiciones de activos locales (CEPAL, 2003 y 2012). 
Por su parte, los Estados Unidos, importante inversor durante todo el siglo XX, se ha mantenido como un gran adquiriente de activos productivos en América Latina, lo que se observa en los niveles de centralidad de grado de salida, que se incrementaron en el bienio anterior a la crisis. Por su parte, se registra un notable aumento de dicho indicador en el caso del Brasil, que responde al auge de la expansión internacional de sus empresas desde mediados de la década de 2000 (CEPAL, 2005 y 2014). Las empresas translatinas brasileñas se ven favorecidas por la relevante política de apoyo que aplica el sector público, pudiéndose destacar en este aspecto la que lleva adelante el Banco de Desarrollo del Brasil (BNDES). Por su parte, México sobresale en posiciones de mayor centralidad de salida en la red en el período anterior a la recesión de 2009.

En referencia al atractivo de los países como destino de inversión, destacan el Brasil y México y, en menor medida, la Argentina y Chile. Estas economías han realizado profundas reformas estructurales que han facilitado el ingreso y la rentabilidad de las empresas extranjeras. Además, en el caso del Brasil y México habría que añadir el considerable tamaño del mercado interno, que aparece como una importante ventaja de localización para los inversionistas extranjeros. No obstante, las diferencias a lo largo del período son significativas. Destaca el deterioro sufrido por la posición de la Argentina, que pasó de tener una elevada centralidad de grado de entrada a finales de los años noventa a registrar niveles muy bajos en los últimos años del período analizado. La incertidumbre iniciada con la ruptura de la convertibilidad en 2001, que dio lugar a numerosos casos de denuncias ante el Centro Internacional de Arreglo de Diferencias Relativas a Inversiones (CIADI) (Stanley, 2004; Zabalo Arena, 2012), ha tenido su reflejo en una pérdida de los niveles de centralidad de la que el país no se ha recuperado durante el siglo XXI (véase el gráfico 2).

No han de extrañar los relativamente bajos niveles de centralidad de entrada que presentan los Estados Unidos y España, debido a que, en la forma como se ha construido la red, solo quedan recogidas las adquisiciones que empresas de América Latina hayan hecho de compañías españolas o estadounidenses. De este modo, se pone de manifiesto que las translatinas son aún relativamente poco activas en su expansión fuera de la región.

Desde otra perspectiva, es posible analizar el grado de vinculación de un país con los actores más influyentes de la red, a través de la centralidad de vector propio. El Brasil y España, seguidos por los Estados Unidos, México y la Argentina, son los países con mayor centralidad de vector propio, por lo que la transferencia de información y conocimiento, las transformaciones en las formas de organización empresarial, recursos humanos, disponibilidad de información y, en términos generales, la concentración de poder gira en torno a dichos países (véase el gráfico 3). Al realizar un análisis temporal, destaca la progresiva pérdida de influencia, medida por la centralidad de vector propio, de países como México o el Reino Unido. Asimismo, hay que destacar la irrupción de China, que, habiendo estado ausente durante todo el período, en el bienio 2010-2011 alcanza una centralidad superior a la de España, ocupando el segundo puesto, tras el Brasil.

Por lo tanto, pese al aumento de la centralización global de la red (debido principalmente al papel del Brasil), durante este período han surgido otros centros de intercambio de información y de dinamismo en la transferencia de experiencias, aprendizaje, tecnología y otros factores, diferentes a los tradicionales como España, los Estados Unidos o México. Economías tan diversas como Colombia, Chile o China han comenzado a cobrar importancia relativa en las interacciones estudiadas. 


\section{Gráfico 3}

Países seleccionados: centralidad de vector propio en las fusiones y adquisiciones transfronterizas de empresas, 1999-2012

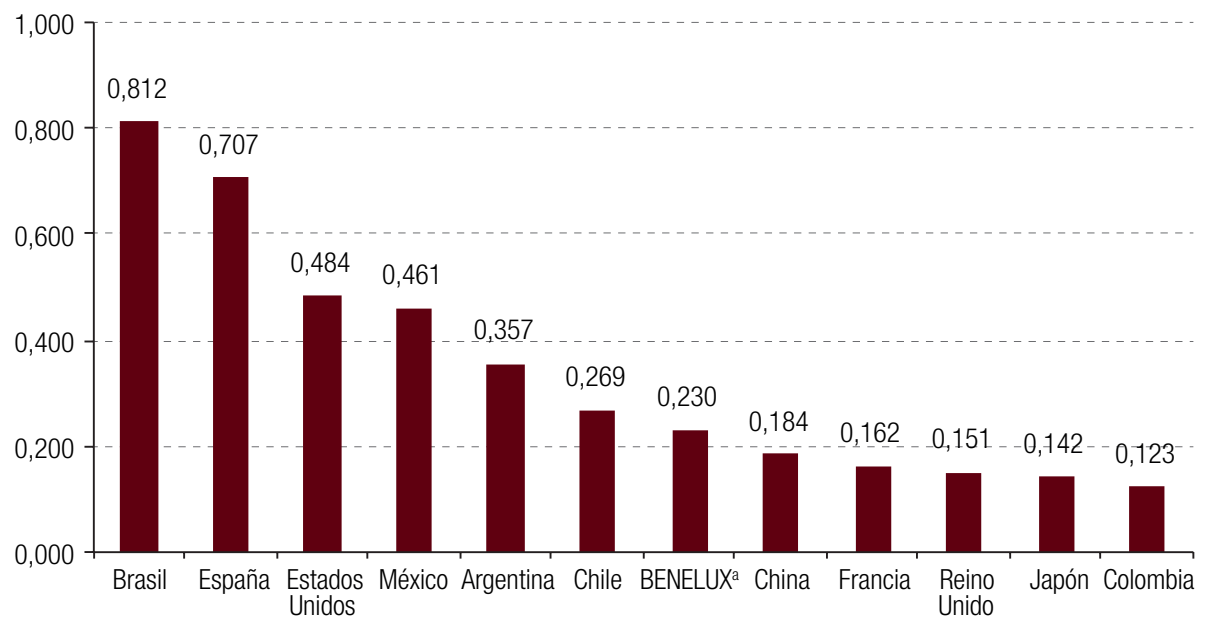

Fuente: Elaboración propia.

a Unión Económica Bélgica-Países Bajos-Luxemburgo.

\section{Las fusiones y adquisiciones en los sectores de telecomunicaciones, energía y finanzas: dinámica regional y papel de España}

La segmentación de las fusiones y adquisiciones según los sectores productivos en que se insertan las empresas permite un análisis diferenciado para observar los comportamientos propios de cada sector. En este caso se seleccionaron los sectores de servicios en que las transnacionales españolas han sido más dinámicas en América Latina: las telecomunicaciones, la energía y las finanzas (véanse el cuadro 4 y el gráfico 4).

El análisis de las características estructurales de estas redes (véase el cuadro 4) permite llegar a las siguientes conclusiones:

- La interacción entre países, medida a través de la densidad, es superior en los sectores de la energía y las finanzas, y menor en el sector de las telecomunicaciones. Frente a las numerosas entidades de la banca y la energía instaladas en América Latina, el mercado de las telecomunicaciones está básicamente controlado por dos grandes operadores.

- Las redes sectoriales muestran niveles de concentración, medidos a través de la centralización, inferiores a los de la red total. Esto significa que las fusiones y adquisiciones en los sectores de la energía, las telecomunicaciones y las finanzas involucran a un mayor número de países de forma activa, como consecuencia de que la gran mayoría de los países han liberalizado dichos sectores de servicios de utilidad pública, permitiendo el ingreso de capital extranjero, que se ha instalado en dichas economías a partir de la adquisición de activos ya existentes.

En cada uno de los sectores se puede observar cuál es la posición de España respecto del total de los países, así como respecto de aquellos con los que se disputa las posiciones más influyentes, particularmente el Brasil y los Estados Unidos, aunque existen singularidades que se señalarán en el caso de cada sector. 


\title{
Cuadro 4
}

Características estructurales de las redes de fusiones y adquisiciones transfronterizas de empresas en América Latina en sectores seleccionados

\begin{tabular}{lcccc}
\hline & Energía & Finanzas & Telecomunicaciones & Global \\
\hline Densidad & 0,104 & 0,108 & 0,066 & 0,279 \\
\hline Centralización de grado total & 0,036 & 0,040 & 0,032 & 0,081 \\
\hline
\end{tabular}

Fuente: Elaboración propia.

\author{
Gráfico 4
}

Redes de fusiones y adquisiciones transfronterizas de empresas en América Latina en sectores seleccionados, 1999-2012

\section{A. Energía}

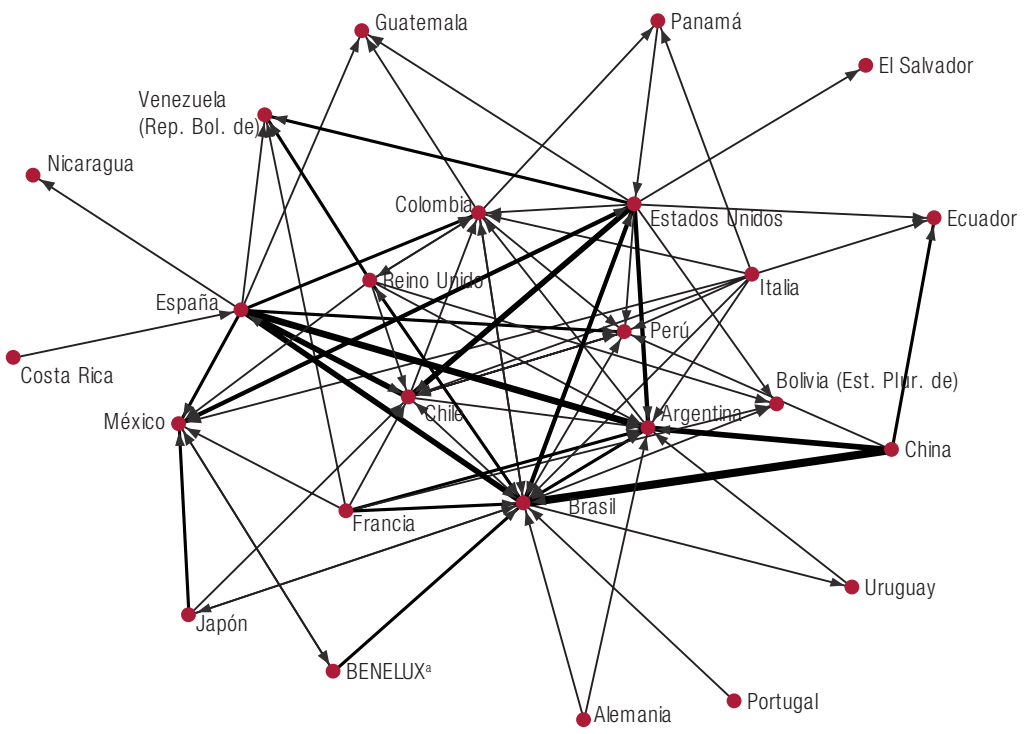

B. Finanzas

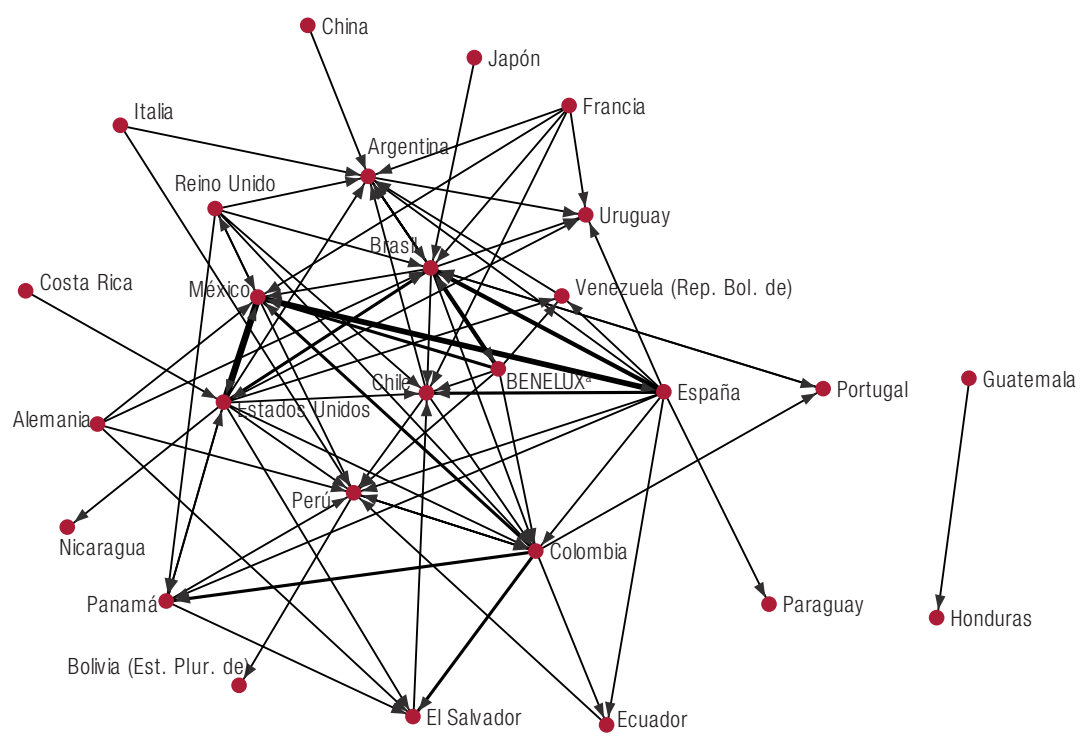




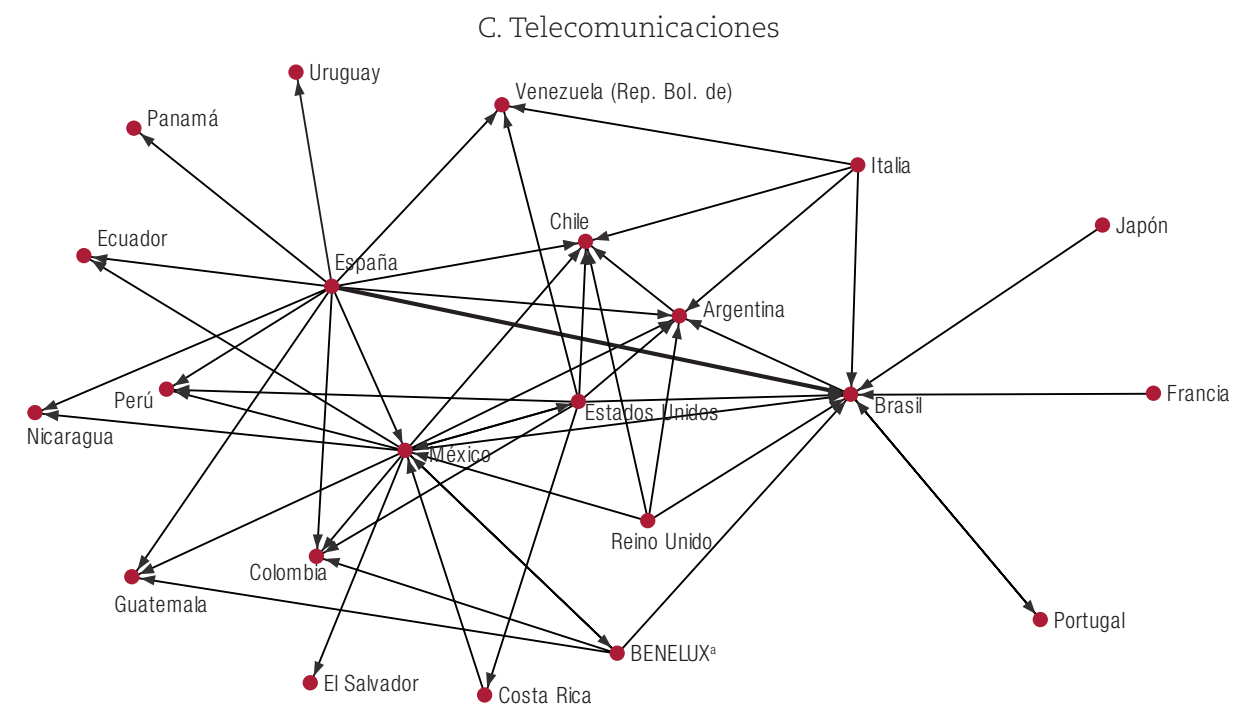

Fuente: Elaboración propia.

a Unión Económica Bélgica-Países Bajos-Luxemburgo.

En el caso del sector de la energía, España muestra un mayor protagonismo en las adquisiciones de empresas latinoamericanas, medido a través de la centralidad de grado de salida, que los Estados Unidos y el Brasil. Compañías como la Empresa Nacional de Electricidad, S.A. (ENDESA) - actualmente de propiedad de la italiana ENEL_, Iberdrola, Gas Natural o Unión Fenosa -las dos últimas hoy fusionadas en Gas Natural Fenosa - han sido muy activas en su expansión en la región. En la década de 1990, estas empresas comenzaron a modificar su estructura de negocio para poder ajustarse a los cambios legislativos derivados de la liberalización de los sectores de electricidad y gas impuestos por la Unión Europea. Ello obligó no solo a operar en régimen de competencia, sino también a separar verticalmente los mercados de generación, distribución y comercialización. Además, los nuevos desarrollos tecnológicos ligados a la generación de electricidad a través de turbinas de ciclo combinado vincularon los negocios de la electricidad y el gas. El resultado final fue un proceso de fusiones y adquisiciones en los mercados nacionales y, posteriormente, su expansión internacional. De forma paralela en América Latina, aunque con diferencias entre países, se modificaron los marcos regulatorios de la electricidad (Maldonado y Palma, 2004). En este contexto, las empresas españolas adquirieron activos relevantes en la región, compitiendo con algunas empresas estadounidenses como Enron y AES Corporation, que se habían instalado una década antes en la zona. No obstante, la crisis energética de California y la quiebra de Enron en 2001 dejaron un camino más despejado para las empresas españolas y otras empresas europeas, a la vez que se abrió un espacio para las propias empresas latinoamericanas. Sin embargo, los marcos regulatorios en América Latina han generado grandes incertidumbres y riesgos regulatorios (CEPAL, 2004), por lo que algunas de las economías de mayor tamaño o crecimiento plantean hoy grandes retos en materia de seguridad energética.

Respecto a la centralidad de vector propio en el sector de la energía, se observa que España queda ligeramente desplazada por el Brasil en la posición de país (nodo) central, aunque muy por encima de los Estados Unidos. Como se ha explicado con anterioridad, este indicador muestra la conexión con otros países (nodos) que resultan centrales en la red. Hay que recordar que el Brasil privatizó activos en los sectores de distribución y transmisión, pero que, por el contrario, la privatización de las empresas generadoras quedó interrumpida por la crisis energética del período 2001-2002 (CEPAL, 2012). Además, algunas empresas públicas brasileñas han traspasado las fronteras, como 
Petróleo Brasileiro (Petrobras), que además es una de las pocas compañías en la región, junto con Gas Natural Fenosa, que muestra niveles de integración de las actividades de generación de electricidad y gas natural.

En la red del sector financiero, España destaca como país adquiriente de activos, según la medición de la centralidad de grado de salida, por delante de los Estados Unidos y el Brasil. Los bancos españoles han adquirido numerosos activos, encontrando en América Latina un mercado para la expansión de sus actividades ${ }^{7}$. Además, dichas inversiones les permitieron explotar sus recursos y capacidades organizativas y tecnológicas de una forma global, diversificando el riesgo (CEPAL, 2012). Entidades como el Banco Santander y el Banco Bilbao Vizcaya Argentaria (BBVA) están presentes en casi la totalidad de los países, a los que ingresaron a través de las adquisiciones de bancos nacionales, y aunque los modelos de penetración de ambas entidades no fueron iguales, se pueden señalar algunas pautas comunes, como la búsqueda de un mercado potencialmente muy amplio, por cuanto las tasas de bancarización de los países latinoamericanos eran, en comparación con las registradas en España y el resto de los países de la Unión Europea, muy inferiores (Sánchez Díez, 2002). Por su parte, la menor centralidad de grado de entrada del Brasil tiene una explicación en la importancia de la banca pública y los grupos locales, que ha dificultado el ingreso de bancos extranjeros. No obstante, también han aparecido competidores regionales -colombianos y brasileños - así como europeos - británicos y neerlandeses - que están teniendo una gran penetración en la región.

Al analizar la centralidad de vector propio en el sector financiero se observa que España cuenta con una posición más periférica que los Estados Unidos, reflejo de la presencia histórica de bancos estadounidenses en la región, que se han mantenido y reforzado a lo largo de los años. Aunque la presencia de la banca extranjera en América Latina es muy elevada, representando el $40 \%$ del total (BPI, 2010), la crisis financiera internacional no ha afectado de forma seria al sector bancario latinoamericano (CEPAL, 2012, pág. 144). Las innovaciones financieras y los propios procesos de desregulación se han realizado con cautela, para evitar las experiencias críticas de las debacles financieras y bancarias registradas en las últimas décadas. Este hecho es considerado como una fortaleza de los propios sistemas financieros de la región (Marshall, 2011).

En el sector de las telecomunicaciones, el Brasil y España son los países más centrales de la red, según su centralidad de grado total, seguidos por México, Portugal y la Argentina. El Brasil destaca en la centralidad de grado de entrada y España en la centralidad de grado de salida. En la década de 1990, las empresas de telecomunicaciones en América Latina eran esencialmente monopolios públicos, con grandes deficiencias de infraestructura y calidad en la prestación de servicios, originadas por la falta de financiamiento durante la denominada década perdida. La apertura de la cuenta de capitales y los cambios legislativos, unidos a los procesos de privatizaciones, dieron entrada a empresas extranjeras, tanto europeas como estadounidenses. Pero el cambio de siglo sorprendió al sector con una importante crisis de naturaleza tecnológica, que dio origen a una fuerte reestructuración del negocio, y la masificación del uso de Internet en la vida civil, que transformó la importancia de los servicios prestados, en el sentido de que la telefonía fija ha perdido relevancia en favor de la telefonía móvil y de transmisión de datos.

Algunas de las empresas estadounidenses vendieron sus activos, primando las inversiones en el mercado nacional, y las oportunidades que se abrieron fueron aprovechadas por la empresa española Telefónica, actualmente Movistar, y la mexicana América Móvil. A partir de ese momento, aunque existen otros operadores menores, estas dos grandes empresas se disputan el mercado de las telecomunicaciones de América Latina. Ambas son empresas de integración vertical, que han crecido con la idea de ser líderes nacionales y con una clara vocación de internacionalización. La española apostó, en sus inicios, por el Cono Sur y la telefonía fija, para después abordar el conjunto de

7 En CEPAL (2012, pág. 130) se puede consultar el detalle de las adquisiciones más importantes del período 1990-2011. 
la región y de los mercados de telecomunicaciones, mientras que la mexicana comenzó su expansión por las economías mayores (Brasil) o más próximas (algunos países de Centroamérica), apostando por la telefonía móvil (CEPAL, 2008). El Brasil ha sido el "campo de batalla" de ambas empresas, donde Movistar contó con el apoyo de Portugal Telecom para crear Vivo, el gran operador de telefonía celular del país.

\section{Conclusiones e ideas finales}

El análisis de los indicadores de red permite obtener las siguientes conclusiones vinculadas a cada uno de los objetivos planteados en el estudio:

i) Respecto al objetivo 1, referido al análisis de la estructura de la red de fusiones y adquisiciones, se destacan los siguientes resultados en relación con las interacciones entre economías y la concentración de las operaciones en un conjunto de países:

- La estructura de la red global del período 1999-2012 presenta un reducido grupo de países centrales, frente a los demás, que se sitúan en la periferia; es decir, hay unos países altamente interconectados a través de flujos de fusiones y adquisiciones, frente a otro conjunto de países con menor interdependencia y que se sitúan, por lo tanto, al margen de los procesos de reordenación de la propiedad de los activos productivos. Al analizar la evolución a lo largo del período estudiado, se observa que los mayores niveles de interacción se han alcanzado durante los períodos 2007-2009 y 2010-2011. Ello es resultado de la coexistencia de las estrategias de adquisición de activos de las empresas que tradicionalmente han sido importantes inversionistas en la región, como las españolas y las estadounidenses, con el despegue de ciertas economías latinoamericanas como emisoras de inversión.

- Los niveles de concentración de la red, medidos a través de la centralización, alcanzan los niveles más elevados entre 2007 y 2011, lo que pone de manifiesto el incremento en esos años de la importancia de un menor número de países, frente a un reparto más equitativo en los años anteriores.

Por lo tanto, se está configurando un núcleo central de países que participan más activamente en la reordenación de activos latinoamericanos, de forma que la expansión del capital productivo está reforzando un núcleo duro de economías en las que se concentran los efectos de transvase y las potenciales transformaciones del tejido productivo.

ii) En cuanto al objetivo 2, relativo al estudio de la posición de España en la red de fusiones y adquisiciones respecto de los potenciales competidores, se han encontrado los siguientes hechos:

- Al analizar la posición que ocupa cada país en la red se observan cuatro tipos de países: i) aquellos que se destacan por su centralidad total, ya sea como países inversores o como países receptores, caso en que se encuentran claramente el Brasil, los Estados Unidos y México; ii) aquellos que ocupan una posición central en la red, como consecuencia de la relevante ubicación que adquieren en su condición de inversores, como España; iii) aquellos que tienen una posición central como resultado de la venta de activos, como la Argentina, aunque con una tendencia a perder importancia muy marcada a lo largo de los años, y iv) aquellos que se encuentran en la periferia de la red, escasamente conectados con los países centrales de la periferia y unidos por vínculos muy débiles.

- En cuanto a España, se observa que se mantiene en posiciones centrales de la red, con mayor claridad en los períodos 1999-2000 y 2003-2004. La aparición de nuevos competidores no ha desplazado a España a posiciones periféricas, aunque se ha traducido en una transformación de la estructura de la red, debido al aumento de los países que se ubican en posiciones centrales. 
- Entre los países que pueden competir con España por las posiciones centrales de la red, destaca principalmente el Brasil, por su capacidad para atraer inversión, así como su creciente fortaleza como país inversor, en particular desde 2007. Por su parte, las empresas de los Estados Unidos han adquirido empresas latinoamericanas durante todo el período, pero además desde 2007 se observa que también se incrementa la centralidad de grado de entrada de ese país, lo que muestra que empresas translatinas están adquiriendo activos en dicha economía. También destacan, aunque en menor medida, Colombia y Chile, que han sido receptores de inversión por transferencia de activos a manos extranjeras y cuyas empresas, según se observa en los últimos años, se están internacionalizando, dirigiéndose en particular a economías próximas. Finalmente, China muestra en el período 2010-2011 un importante protagonismo como país inversor, debido a que muchas de sus empresas han salido al exterior en busca de materias primas para abastecer el crecimiento de la economía nacional.

Por lo tanto, se concluye que España se mantiene en el centro de la red, aunque con crecientes y poderosos competidores, entre los que destacan el Brasil y los Estados Unidos, así como probablemente China, en un futuro próximo.

iii) Finalmente, como resultado del análisis de la estructura de las redes sectoriales (objetivo 3), se han obtenido las siguientes conclusiones:

- Los países presentan mayores interacciones en las redes de los sectores de la energía y las finanzas que en las telecomunicaciones.

- La concentración de las redes sectoriales es menor que la global. No obstante, hay que señalar que mientras que en el caso de las finanzas hay mayores diferencias entre la centralidad de grado de entrada y la de salida, en el caso de las telecomunicaciones y la energía la concentración es similar.

Existen, por lo tanto, diferencias sustanciales entre las redes sectoriales, con mayores interacciones en los sectores de la energía y las finanzas. Los niveles de concentración del poder son inferiores a los globales.

En resumen, se puede afirmar que la estructura de la red de fusiones y adquisiciones de empresas en América Latina muestra la existencia de un núcleo central de países que concentra las operaciones de adquisiciones de activos y, en consecuencia, cuenta con un mayor acceso a la producción de transvase de conocimientos, cesión de tecnología o aprendizaje de nuevas formas de organización empresarial. Frente a esta situación, hay un número amplio de países que permanecen en la periferia de la red. España se mantiene en posiciones centrales, aunque con poderosos competidores.

\section{Bibliografía}

Aitken, B.J. y A.E. Harrison (1999), "Do domestic firms benefit from direct foreign investment? Evidence from Venezuela", American Economic Review, vol. 89, №3, Nashville, Tennessee, American Economic Association.

Álvarez, I. y C. Torrecillas (2013), "Factores determinantes de la emisión de inversión extranjera directa", Revista de Economía Mundial, № 34, Huelva, Sociedad de Economía Mundial.

Amir, R. y N. Lazzati (2011), "Network effects, market structure and industry performance", Journal of Economic Theory, vol. 146, № 6, Amsterdam, Elsevier.

Bearman, P., J. Moody y K. Stovel (2004), "Chains of affection: the structure of adolescent romantic and sexual networks", American Journal of Sociology, vol. 110, № 1.

Blomström, M. y A. Kokko (2003), "The economics of foreign direct investment incentives", Foreign Direct Investment in the Real and Financial Sector of Industrial Countries, H. Heinz Herrmann y R. Lipsey, Berlín, Springer.

Bonacich, P. (1972), "Factoring and weighting approaches to clique identification", Journal of Mathematical Sociology, vol. 2, № 1, Taylor \& Francis. 
BPI (Banco de Pagos Internacionales) (2010), "Long-term issues in international banking", CGFS Paper, $N^{\circ} 41$, Basilea, Comité del Sistema Financiero Mundial.

Calvó-Armengol, A. y M. Jackson (2004), "The effects of social networks on employment and inequality", American Economic Review, vol. 94, №3, Nashville, Tennessee, American Economic Association.

Casson, M.C. (1985), "The theory of foreign direct investment", The Economic Theory of the Multinational Enterprise, P.J. Buckley y M. Casson, Londres, Macmillan. (1979), Alternatives to the Multinational Enterprise, Londres, Macmillan.

Caves, R.E. (1982), "Investment, and location policies of multinational companies", Zeitschrift für Volkswirtschaft und Statistik, № 3.

(1980), Multinational Enterprise and Economic Analysis, Cambridge, Massachusetts, Cambridge University Press.

(1971), "International corporations: the industrial economics of foreign investment", Economica, vol. 38, № 149, Wiley.

Caves, R. y R.C. Hirschey (1981), "Research and transfer of technology by multinational enterprises", Oxford Bulletin of Economics and Statistics, vol. 43, № 2, Oxford, Basil Blackwell.

CEPAL (Comisión Económica para América Latina y el Caribe) (2014), La inversión extranjera directa en América Latina y el Caribe, 2013 (LC/G.2613-P), Santiago. (2012), La inversión extranjera directa en América Latina y el Caribe, 2011 (LC/G.2538-P), Santiago. (2011), La inversión extranjera directa en América Latina y el Caribe, 2010 (LC/G.2494-P), Santiago. (2008), La inversión extranjera directa en América Latina y el Caribe, 2007 (LC/G.2360-P), Santiago. (2005), La inversión extranjera directa en América Latina y el Caribe, 2004 (LC/G.2447-P), Santiago. (2004), La inversión extranjera directa en América Latina y el Caribe, 2003 (LC/G.2226-P), Santiago. (2003), La inversión extranjera directa en América Latina y el Caribe, 2002 (LC/G.2198-P), Santiago.

Chinazzi, M. y otros (2013), "Post-mortem examination of the international financial network", Journal of Economic Dynamics and Control, vol. 37, № 8, Amsterdam, Elsevier.

De Benedictis, L. y otros (2013), "Network analysis of world trade using the BACl-CEPIl dataset", CEPII Working Paper, № 24.

Dunning, J.H. (2009), "Location and the multinational enterprise: a neglected factor?, Journal of International Business Studies, vol. 40, № 1, Palgrave Macmillan.

(1994), "Re-evaluating the benefits of foreign direct investment", Transnational Corporations, vol. 3, № 1 , Ginebra, Conferencia de las Naciones Unidas sobre Comercio y Desarrollo (UNCTAD).

_ (1988), "The eclectic paradigm of international production: a restatement and some possible extension", Journal of International Business Studies, vol. 19, № 1, Palgrave Macmillan.

_ (1980), "Toward an eclectic theory of international production", Journal of International Business Studies, vol. 11, № 1, Palgrave Macmillan.

(1979), "Explaining changing patterns of international production: in defence of the eclectic theory", Oxford Bulletin of Economics and Statistics, vol. 41, N 4, Universidad de Oxford.

(1977), "Trade, location of economic activity and MNE: a search for an eclectic approach", The International Allocation of Economic Activity, B. Ohlin, P.O. Hesselborn y P.J. Wiskman (eds.), Londres, Macmillan.

Elliott, M., B. Golub y M. Jackson (2014), "Financial networks and contagion” [en línea] http://www.its.caltech. edu/ melliott/papers/financial_networks.pdf.

Fagiolo, G., J. Reyes y S. Schiavo (2009), "The world-trade web: topological properties, dynamics, and evolution", Physical Review E, vol. 79, American Physical Association.

Fleming, L., C. King y A. Juda (2007), "Small worlds and regional innovation", Organization Science, vol. 18, $N^{\circ} 6$.

Galaso, P. (2011), "El papel del capital social en el desarrollo. Un estudio de las redes de innovación en España", Nuevos enfoques del desarrollo. Una mirada desde las regiones, L. Gutiérrez y M. Limas (coords.), Ciudad Juárez, Universidad Autónoma de Ciudad Juárez.

Haberly, D. y D. Wojcik (2013), "Regional blocks and imperial legacies: mapping the global offshore FDI network", Working Papers in Employment, Work and Finance, № 13-07, Universidad de Oxford.

Hymer, S.H. (1979), The Multinational Corporation, Cambridge, Massachusetts, Cambridge University Press. (1976), The International Operations of National Firms: a Study of Direct Foreign Investment, Cambridge, Massachusetts, The MIT Press.

Jackson, M. (2008), Social and Economic Networks, Princeton, Princeton University Press.

Jackson, M. y A. Wolinsky (1996), "A strategic model of social and economic networks", Journal of Economic Theory, vol. 71, № 1, Amsterdam, Elsevier. 
Kali, R. y J. Reyes (2006), "The architecture of globalization: a network approach to international economic integration", Journal of International Business Studies, vol. 38, № 4, Palgrave Macmillan.

Kindleberger, C. (1969), American Business Abroad. Six Lectures on Direct Investment, New Haven, Yale University Press.

Luo, Y. y R. Tung (2007), "International expansion of emerging market enterprises: a springboard perspective", Journal of International Business Studies, vol. 38, № 4, Palgrave Macmillan.

Maldonado, P. y R. Palma (2004), "Seguridad y calidad del abastecimiento eléctrico a más de 10 años de la reforma de la industria eléctrica en países de América del Sur", serie Recursos Naturales e Infraestructura, № 72 (LC/L.2158-P), Santiago, Comisión Económica para América Latina y el Caribe (CEPAL).

Marshall, E. (2011), "Desarrollo financiero en América Latina: avances y desafíos", Documentos de Política Económica, № 43, Santiago, Banco Central de Chile.

Mathews, J.A. (2006), "Dragon multinationals: new players in 21st century globalization", Asia Pacific Journal of Management, vol. 23, $N^{\circ} 1$, Springer.

Mitchell, M. y A. Skrzypacz (2006), "Network externalities and long-run market shares", Economic Theory, vol. 29, $\mathrm{N}^{\circ}$ 3, Springer.

Moon, H. y T.W. Roehl (2001), "Unconventional foreign direct investment and the imbalance theory", International Business Review, vol. 10, № 2, Amsterdam, Elsevier.

Rodrik, D. (2011), La paradoja de la globalización. Democracia y el futuro de la economía mundial, Barcelona, Antoni Bosch Editor.

Rugman, A.M. (1981), Inside the Multinationals: the Economics of Internal Markets, Nueva York, Columbia University Press.

- (1980), "Internationalization as a general theory of foreign direct investment: a re-appraisal of the literature", Weltwirtschafliches Archiv, vol. 116.

_ (1976), "Risk reduction by international diversification", Journal of International Business Studies, vol. 7 , $N^{\circ}$ 2, Palgrave Macmillan.

Sánchez Díez, A. (2002), La internacionalización de la economía española hacia América Latina: Ios elementos determinantes en el inicio y la consolidación del proceso, Burgos, Universidad de Burgos.

Schilling, M.A. y C.C. Phelps (2007), "Interfirm collaboration networks: the impact of large-scale network structure on firm innovation", Management Science, vol. 53, No 7.

Stanley, L. (2004), "Acuerdos bilaterales de inversión y demanda ante tribunales internacionales: la experiencia argentina reciente", serie Desarrollo Productivo, № 158 (LC/L.2181-P), Santiago, Comisión Económica para América Latina y el Caribe (CEPAL).

Tecee, D.J. (1986), "Transactions cost economics and the multinational enterprise", Journal of Economic Behaviour of Organization, vol. 7, № 1, Amsterdam, Elsevier.

Teece, D., G. Pisano y A. Shuen (1997), "Dynamic capabilities and strategic management", Strategic Management Journal, vol. 18, № 7 .

UNCTAD (Conferencia de las Naciones Unidas sobre Comercio y Desarrollo) (s/f), UNCTADSTAT [en línea] http://unctadstat.unctad.org/EN/Index.html.

Visintin, S. (2011), "A network approach to services internationalization", documento presentado en el XIV Encuentro de Economía Aplicada, Huelva, Universidad de Huelva.

Vitali, S., J.B. Glattfelder y S. Battiston (2011), "The network of global corporate control", PLoS ONE, vol. 6, $N^{\circ} 10$.

Vitali, S. y S. Battiston (2013), "The community structure of the global corporate network" [en línea] https:// arxiv.org/pdf/1301.2363v1.pdf.

Wasserman, S. y K. Faust (1994), Social Network Analysis. Methods and Applications, Cambridge, Cambridge University Press.

Watts, D. y S. Strogatz (1998), "Collective dynamics of 'small-world' networks", Nature, vol. 393.

Williamson, O.E. (1975), Markets and Hierarchies: Analysis and Antitrust Implications. A Study of the Economics of Internal Organization, Nueva York, Free Press.

Zabalo Arena, P. (2012), "América Latina ante las demandas inversor-Estado", Revista de Economía Mundial, $N^{\circ} 31$, Sociedad de Economía Mundial. 